\title{
Body mass index, waist circumference, and risk of hearing loss: a meta-analysis and systematic review of observational study
}

\author{
Jin-Rong Yang ${ }^{1}$, Khemayanto Hidayat ${ }^{1}$, Cai-Long Chen ${ }^{1,2}$, Yun-Hong Li ${ }^{1}$, Jia-Ying $\mathrm{Xu}^{3}$ and Li-Qiang Qin ${ }^{1 *}$
}

\begin{abstract}
Background: Emerging evidence implicates excess weight as a potential risk factor for hearing loss. However, this association remained inconclusive. Therefore, we aimed to systematically and quantitatively review the published observational study on the association between body mass index (BMI) or waist circumference (WC) and hearing loss.

Methods: The odds ratios (ORs) or relative risks (RRs) with their 95\% confidence intervals (Cls) were pooled under a random-effects model. Fourteen observational studies were eligible for the inclusion in the final analysis.

Results: In the meta-analysis of cross-sectional studies, the ORs for prevalent hearing loss were $1.10(95 \% \mathrm{Cl} 0.88$, 1.38) underweight, 1.14 ( $95 \% \mathrm{Cl} 0.99$, 1.32) for overweight, OR 1.40 ( $95 \% \mathrm{Cl} 1.14,1.72)$ for obesity, 1.14 ( $95 \% \mathrm{Cl} 1.04$, 1.24) for each $5 \mathrm{~kg} / \mathrm{m}^{2}$ increase in BMl, and 1.22 (95\% CO 0.88. 1.68) for higher WC. In the meta-analysis of longitudinal studies, the RRs were $0.96(95 \% \mathrm{Cl} 0.52$, 1.79) for underweight, $1.15(95 \% \mathrm{Cl} 1.04,1.27)$ for overweight, $1.38(95 \% \mathrm{Cl} 1.07,1.79)$ for obesity, $1.15(95 \% \mathrm{Cl} 1.01,1.30)$ for each $5 \mathrm{~kg} / \mathrm{m}^{2}$ increase in BMl, and $1.11(95 \% \mathrm{Cl} 1.01$, 1.22) for higher WC.
\end{abstract}

Conclusions: In summary, our findings add weight to the evidence that elevated BMI and higher WC may be positively associated with the risk of hearing loss.

Keywords: Hearing loss, Obesity, Overweight, Body mass index, Waist circumference, Adiposity

\section{Introduction}

Hearing loss is a growing important global public health concern. In 2018, the World Health Organization (WHO) estimated there were 466 million $(6.1 \%$ of the world's population) people living with disabling hearing loss worldwide. The number of people with hearing loss is projected to increase to 630 million by 2030 and to 900 million in 2050 [1]. Between 1990 and 2016, hearing loss move up from the fifth to the third major cause of years lived with disability [2]. Hearing loss is not only

\footnotetext{
* Correspondence: qinliqiang@suda.edu.cn

'Department of Nutrition and Food Hygiene, School of Public Health, Soochow University, Suzhou 215123, China

Full list of author information is available at the end of the article
}

restricting individuals' ability to communicate and interact, but may also have a negative impact on physical and psychosocial well-being and quality of life of people with this disability [3-9]. Thus far, genetic predisposition, certain infections, ototoxic drugs, and longstanding exposure to excessive noise have been identified as risk factors for hearing loss [3, 10-12]. Considering that hearing loss may adversely affect physical, mental, and social well-being and quality of life, further identification of preventable or modifiable factors for hearing loss that could be useful to prevent or at least delay this condition should be a top public health priority.

Emerging evidence implicates excess weight [13] and its related cardiometabolic comorbidities, such as 
diabetes mellitus (DM) [14] and cardiovascular disease (CVD) [15-17], as potential risk factors for hearing loss. These associations are biologically plausible because individuals with these conditions are likely to have poor microvascular circulation that can lead to reduced blood supply to the cochlea, resulting in damage to the hair cells and eventually in hearing loss $[12,13,18]$. In the past few years, the findings of several epidemiological studies [19-28] have indicated that elevated body mass index (BMI), in the obesity range, and to a lesser extent, in the overweight range, was positively associated with hearing loss. However, the association between excess body weight and hearing loss remained inconclusive, as other studies found no association between both conditions [29-32]. Amid this uncertainty, some studies [19, 23] found that underweight was also positively associated with hearing loss.

Given these considerations, we aimed to perform a systematic review and meta-analysis of observational studies to provide further clarification of the potential association between BMI and hearing loss (primary aim). In addition, we also investigated the potential association between marker of central adiposity, waist circumference (WC), and hearing loss (secondary aim).

\section{Methods}

\section{Search strategy}

The present systematic review and meta-analysis followed the Meta-analysis Of Observational Studies in Epidemiology checklist [33]. Two investigators (J.-R.Y. and K.H.) independently performed the literature search, study selection, data extraction, and quality assessment.

The PubMed and Web of Science databases were used to identify the relevant articles in any language that were published from inception to May 2019. We used the following search terms to identify the relevant articles: (hearing OR hearing loss OR hearing impairment OR deaf OR deafness) AND (adiposity OR body fatness OR body size OR anthropometric OR body mass index OR waist circumference OR underweight OR overweight OR obesity). The references cited in the included studies were also scrutinized to identify additional relevant articles.

\section{Study selection}

The observational studies of any design were selected for the final analysis only if they reported the risk estimates (relative risks (RRs), odds ratios (ORs), or hazard ratios (HRs)) with their corresponding 95\% confidence intervals (CIs) of the association between BMI or WC and hearing loss in adults. Studies that specifically enrolled children or adolescents were excluded. If multiple articles reporting the data from the same population were identified, we included only those with the most up-todate, complete, and relevant data.

\section{Data extraction and quality assessment}

The following information were extracted from each included study: the first author's last name, publication year, design, country, age of the participants, proportion of men, total sample and number of cases, exposure category, ascertainment of exposure, ascertainment of hearing loss, definition of hearing loss, and adjustment for confounders. The risk estimates from the maximally adjusted model were included whenever reported. The Newcastle-Ottawa Scale (NOS) [34] was used to judge the quality of the eligible studies. Three domains (selection, comparability, and outcome/exposure) were assessed by the NOS. The cut-off scores of $0-3,4-6$, and 7-9 correspond to low-, moderate-, and highquality study, respectively.

\section{Statistical analysis}

The ORs (from cross-sectional studies) or RRs (from longitudinal studies) with their $95 \%$ CIs were used as the measures of effect size. In the longitudinal study by Barrenas et al. [19], the data were expressed as ORs. However, given the rarity of hearing loss (4\%) among the study population [19], the ORs were approximately equivalent to the RRs [35]. A DerSimonian and Laird random-effects model [36] was used to estimate the summary ORs or RRs with their 95\% CIs for the association between BMI or WC and the risk of hearing loss. The subgroup and meta-regression analyses were not performed owing to the limited number of studies for each association of interest.

In the analysis of BMI, we first investigated the influence of abnormal BMI status (underweight as $<18.5 \mathrm{~kg} /$ $\mathrm{m}^{2}$, overweight as 25.0 to $29.9 \mathrm{~kg} / \mathrm{m}^{2}$, and obesity as $\geq$ $30.0 \mathrm{~kg} / \mathrm{m}^{2}$ ) as classified by the WHO [37] on the risk of hearing loss. If multiple BMI cut-offs that fell into one of the BMI categories as defined by the $\mathrm{WHO}$, we then pooled the RRs or ORs under a fixed-effects model and used the pooled RRs or ORs for that BMI category. In addition, we further investigate the potential linear association between BMI and hearing loss by using the method proposed by Greenland and Longnecker [38] and Orsini et al. [39] to convert BMI categories into a continuous variable for each $5 \mathrm{~kg} / \mathrm{m}^{2}$ increase in BMI.

In the analysis of $\mathrm{WC}$, we only investigated the association between the highest versus lowest WC and hearing loss. The longitudinal study by Cruickshanks et al. [21] was not included in the meta-analysis of WC because the RR was expressed in a continuous variable for each $10 \mathrm{~cm}$ increase in $\mathrm{WC}$.

Additionally, we performed sensitivity analysis by omitting a single study in each turn. 
The $Q$ and $I^{2}$ statistics were used to determine the statistical heterogeneity across studies. For the $Q$ statistic, $P<0.1$ was considered as statistically significant; for the $I^{2}$ statistic, the following cut-off points were used: < 25\% (low heterogeneity), 25-50\% (moderate heterogeneity), > 50-75\% (high heterogeneity), and > 75\% (severe heterogeneity) [40]. Publication bias was statistically assessed using Begg's rank correlation and Egger's regression test [41]. If publication bias was statistically significant, the trim and fill method was performed to adjust the bias [42]. All statistical analyses were performed using STATA software, version 11.0 (STATA Corp., College Station, TX, USA). All $P$ values were twosided, and the level of significance was set at $<0.05$.

\section{Results}

Literature review and study characteristics

The flow chart of study selection and the reasons for exclusion is presented in Fig. 1. During the initial database searches, a total of 4520 articles (1695 from PubMed and 2825 from Web of Science) were identified. After exclusion of duplicates and abstracts/titles screening, 34 articles were eligible for full-text evaluation. After fulltext evaluation, 20 articles were further excluded. Of these excluded articles, 13 studies did not investigate the associations of interest, two studies [43, 44] enrolled adolescents, two studies $[45,46]$ were conducted in the same population as the included study [32], one study [47] comparing low versus high BMI (high BMI as reference), one study [48] investigating the association between hearing loss and obesity, and one study [49] did not report the risk estimate. Finally, 14 studies [19-32], with a total of 489,354 participants and 55,410 cases, were included in the final analysis.

\section{Study characteristics}

Characteristics of the included studies are summarized in Additional file 1 (Table S1). Of the 14 included studies, six were longitudinal studies [19-21, 27-29] and eight were cross-sectional studies [22-26, 30-32]. Twelve studies [19-22, 24-29, 31, 32] were populationbased and two studies [23, 30] were hospital-based. Occupation information was not adequately described in nearly all studies. The mean age of the participants was

4,520 articles identified during initial database searches:

- PubMed database $(n=1,695)$

- Web of Science database $(n=2,825)$

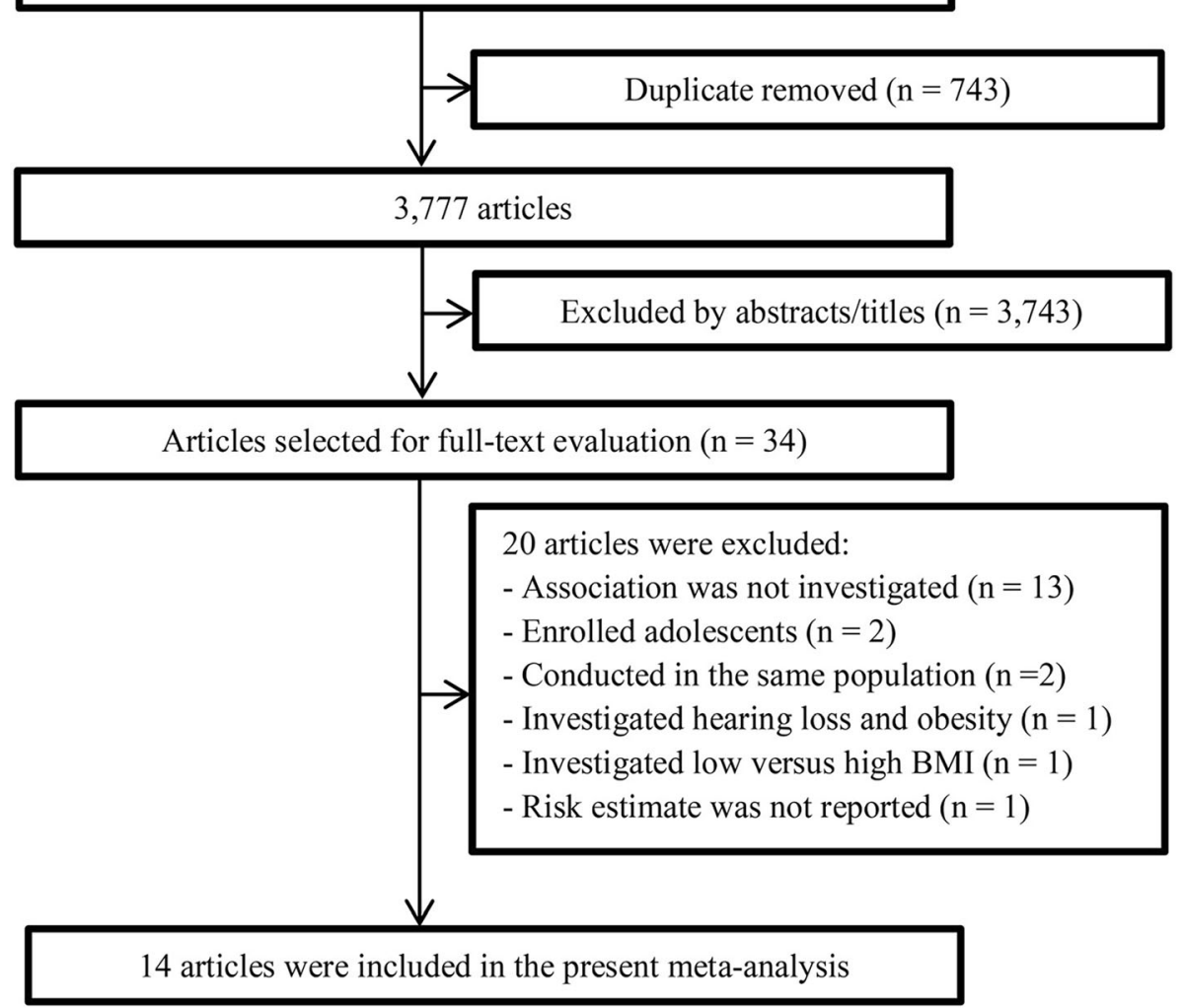

Fig. 1 Flow-chart of the study selection process 
44.8 years. By the sex of the participants, five [19, 22, 24, $29,31]$ studies enrolled men only, two $[20,27]$ enrolled women only, and the remaining seven $[21,23,25,26,28$, $30,32]$ included both men and women. Seven studies [19-22, 25, 27, 29] were conducted in Western countries (Australia, Finland, Sweden, and the USA), six [23, 24, 26, 28, 31, 32] in Asian countries (Bangladesh, China, Iran, Japan, and South Korea), and one [30] in African country (Nigeria). BMI or WC was self-reported in four studies $[20,22,29,31]$, while the remaining ten studies $[19,21,23-28,30,32]$ relied on the data of measured BMI or WC. Hearing loss was measured by pure tone audiometry in 11 studies [19, 21-24, 26-28, 30-32] and self-reported in three studies [20, 25, 29]. The cut-points (frequencies and threshold) used to define hearing loss slightly varied across the studies. The WHO defines hearing loss as pure-tone thresholds of $25 \mathrm{~dB}$ or higher in the better ear or both ears [50]. Thus, the threshold of hearing loss among the included studies that used measured hearing loss was relatively comparable with that of hearing loss according to the WHO definition, with six studies [21, 24, 26, 27, 30, 32] used $25 \mathrm{~dB}$ for hearing loss threshold, three $[19,22,31]$ used $20 \mathrm{~dB}$ as the threshold, one [23] used $26 \mathrm{~dB}$ as the threshold, and one [28] used $40 \mathrm{~dB}$ as the threshold. The information regarding the symmetry of hearing loss (unilateral or bilateral hearing loss) was not adequately described in nearly all studies. Thirteen of the 14 included studies were awarded at least seven stars, which indicated good quality studies (Additional files 2 and 3 Table S2-S3).

\section{Meta-analyses}

\section{Cross-sectional studies}

Pooled cross-sectional studies revealed that obesity was positively associated with the odds of having hearing loss (OR 1.40, 95\% CI 1.14, 1.72; Fig. 2) [22-26, 30]. However, underweight (OR 1.10 95\% CI 0.88, 1.38; Fig. 2) [23, 26, 31], overweight (OR 1.14, 95\% CI 0.99, 1.32; Fig. 2) $[23-26,31,32]$, and higher $\mathrm{WC}(\mathrm{OR} 1.22,95 \% \mathrm{CO}$ 0.88 , 1.68; Fig. 2) $[25,26]$ were not associated with hearing loss. Each $5 \mathrm{~kg} / \mathrm{m}^{2}$ increase in BMI [23-26] was associated with $14 \%$ increased odds of having hearing loss (Fig. 2). High heterogeneity was observed in all analyses $\left(I^{2} \geq 50.7\right)$. There was no evidence of publication bias in all analyses (all $P$ Begg's $\geq 0.17$; all $P$ Egger's $\geq 0.18$ ).

\section{Longitudinal studies}

Pooled longitudinal studies showed that overweight (1.15, 95\% CI 1.04, 1.27; Fig. 3) [19, 20, 27-29], obesity (RR 1.38, 95\% CI 1.07, 1.79; Fig. 3) [19-21, 27-29], and higher WC (RR 1.11, 95\% CI 1.01, 1.22; Fig. 3) [20, 28] were associated with an increased risk of hearing loss. No association was observed between underweight [23, 26,31 ] and the risk of hearing loss (RR 0.96, 95\% CI
0.52, 1.79). Each $5 \mathrm{~kg} / \mathrm{m}^{2}$ increase in BMI $[19,20,28$, 29 ] was associated with a $15 \%$ higher risk of hearing loss (Fig. 3). High heterogeneity was evident in all analyses $\left(I^{2} \geq 54.9\right)$. There was no evidence of publication bias in all analyses (all $P$ Begg's $\geq 0.19$; all $P$ Egger's $\geq 0.12$ ).

\section{Discussion}

To the best of our knowledge, the present study is the first to systematically and quantitatively review the association between BMI or WC and hearing loss. Our findings indicated that elevated body mass index (BMI), particularly in the obesity range, and higher WC were positively associated with hearing loss. The findings of the positive association between elevated BMI and hearing loss were further supported by the linear relationship between BMI and hearing loss.

\section{Potential mechanisms}

The underlying biological mechanisms by which excess weight may play a role in the development of hearing loss are poorly understood. Adipose tissue is an endocrine organ that secretes a number of pro-inflammatory and anti-inflammatory adipokines [51]. Excess adiposity promotes pro-inflammatory state that downregulates anti-inflammatory adipokines and upregulates proinflammatory adipokines [52], leading to vascular dysfunction and damage to the end-organs [53], cochlea in the case of hearing loss [54]. Adiponectin is an antiinflammatory adipokine that may play important roles in the regulation of metabolism, insulin sensitivity, inflammation, and atherosclerosis [55]. Obesity is associated with low levels of plasma adiponectin [56]. Increased levels of plasma adiponectin have been shown to be inversely associated with a high-frequency hearing loss in human, suggesting that low levels of plasma adiponectin may potentially contribute to the development hearing loss [57]. The findings from two animal studies [58, 59] further support the potential role of adiponectin in the development of hearing loss. The first study [58] confirmed the expression of adiponectin receptor 1 in the auditory system of mice. Another study [59] showed that adiponectin deficiency exacerbated age-related hearing loss in knockout mice.

\section{Interpretation}

Study design did not appear to alter the association between BMI and hearing loss, as the positive linear relationship between BMI and hearing loss were evident in both cross-sectional and cohort studies. However, two $[20,29]$ of the included longitudinal studies were relied on the data of self-reported BMI and hearing loss, although the authors of both studies indicated that selfreported BMI was validated and self-reported hearing loss could be a reliable assessment. Amid this 


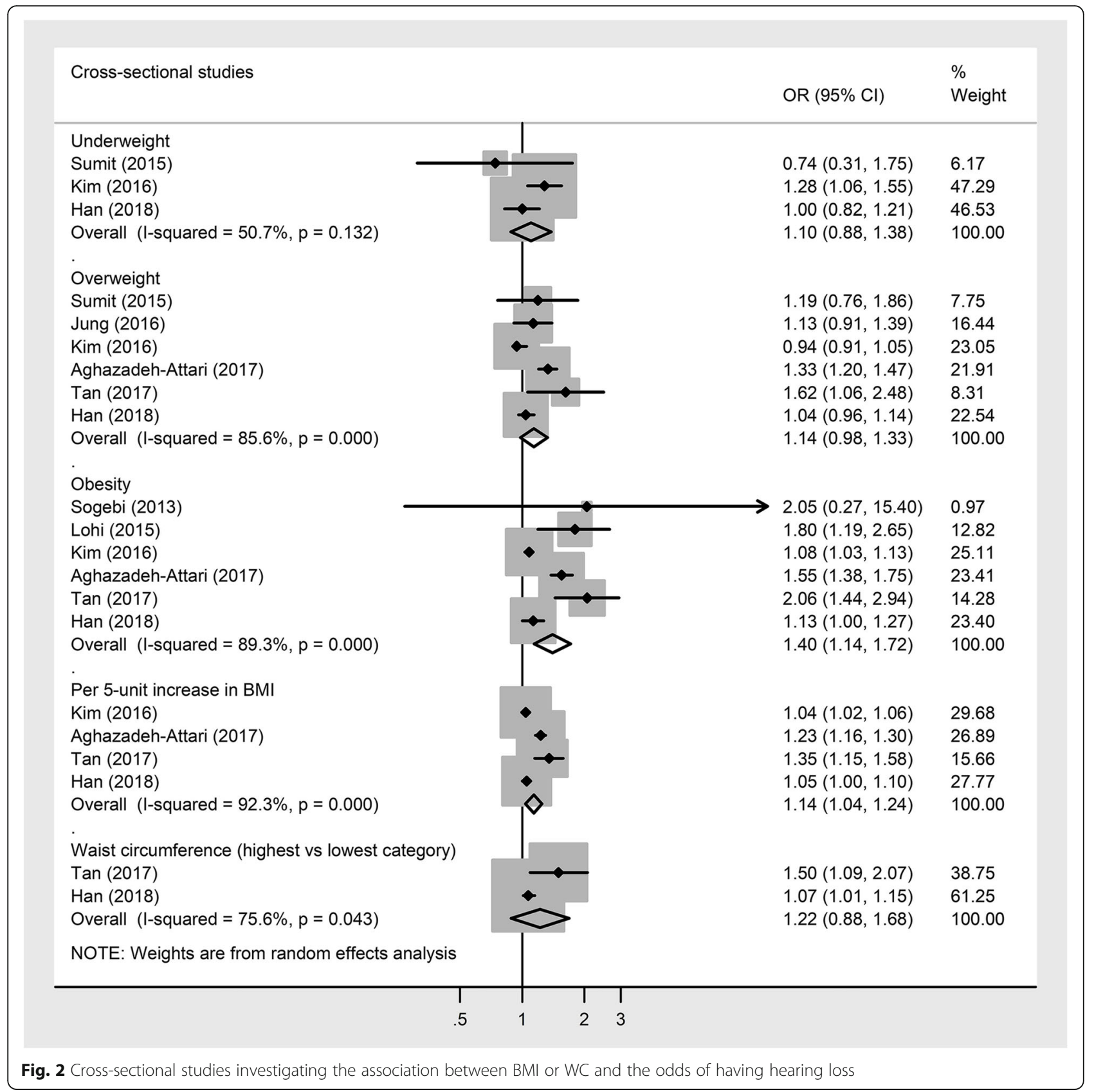

assessment concern, the positive association between measured BMI and measured hearing loss was also evident in several longitudinal studies [19, 21, 27].

Age is a well-established risk factor for hearing loss, as hearing tends to gradually worsen with age [60]. Thus, it is possible that age may modify the positive association between overweight or obesity and hearing loss. Unfortunately, subgroup analyses according to age could not be performed owing to the limited number of studies. However, the majority of studies [20-23, 25-29, 31, 32] have considered age in their analyses, thus the potential biasing influence of age could be minimized. Moreover, obesity during adolescence has been shown to be positively associated with prevalent hearing loss [42, 43].

The positive association between BMI and hearing loss could also be mediated or confounded by the cardiometabolic comorbidities related to excess weight. DM [14, 58, 59] and, to the lesser extent, CVD [15-17] and its cardiovascular risk factors [25, 26, 28] have all been shown to be positively associated with hearing loss. Unfortunately, we could not investigate whether the observed positive association between overweight/ 


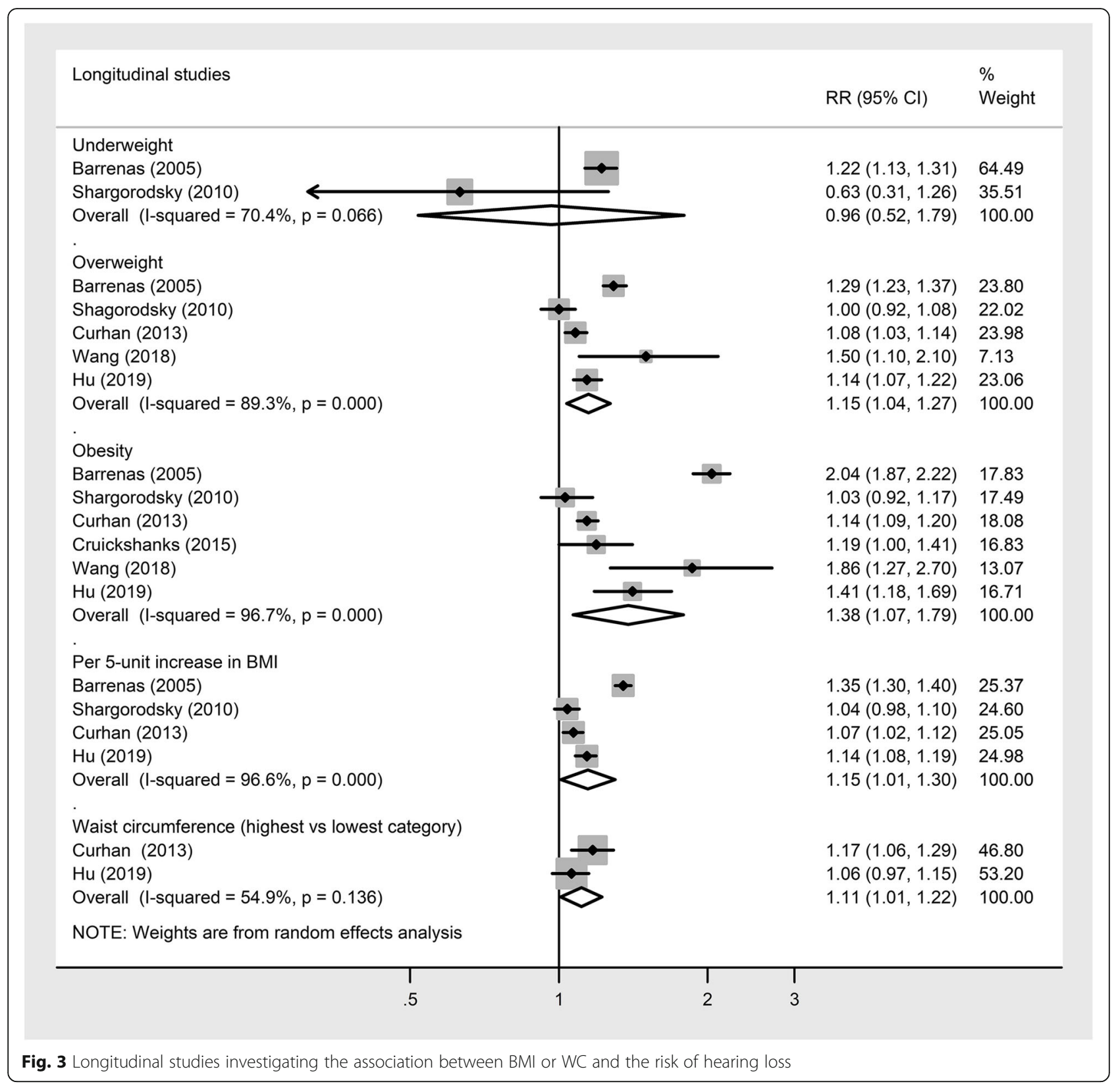

obesity is independent of DM, CVD, or cardiometabolic risk factors owing to the limited studies adjusted for these conditions. The Nurses' Health Study II showed that BMI was associated with the risk of self-reported hearing loss in a dose-dependent manner even after DM and hypertension were taken into consideration [20], whereas the Health Professionals Follow-up found no such association after adjustment for DM, hypertension, and elevated cholesterol [28]. A cross-sectional data from the National Health and Nutrition Examination Survey, 2005 to 2010, showed that adolescent obesity was positively associated with prevalence of hearing loss independent of several cardiometabolic risk factors (high-density lipoprotein level, triglyceride level, elevated blood pressure measurement, hemoglobin A1c level, and C-reactive protein level) [41].

Adipose tissue may differently affect the health risk according to the site of deposition. It has been suggested that excessive accumulation of adipose tissue around the intra-abdominal organs, central adiposity, confers greater risk for cardiometabolic complications of obesity [61]. There is evidence that central adiposity may be more important than overall adiposity in predicting greater risk of cardiometabolic complications related to excess adiposity [62-64], although this is not always the case. As discussed, obesity and its cardiometabolic 
comorbidities may be relevant in the development of hearing loss. On the basis of the aforementioned rationales, WC, a proxy of central adiposity, is expected to be a better predictor for hearing loss than BMI, a proxy for overall adiposity. The findings from cross-sectional studies showed that both elevated BMI and higher WC were associated with poorer hearing thresholds [65-67]. Consistently, both elevated BMI and higher WC were positively associated with hearing loss. However, the relative contribution of BMI and WC to hearing loss has been rarely considered. Notably, only one study [21] on the association between BMI or WC and hearing loss has performed mutual adjustment of BMI and WC, and this study showed that high BMI $\left(25\right.$ to $\left.>40 \mathrm{~kg} / \mathrm{m}^{2}\right)$ and high WC $(>88 \mathrm{~cm})$ were independently associated with an increased risk of hearing loss after mutual adjustment. Nonetheless, future studies need to investigate whether BMI and WC independently contribute to hearing loss.

It is also possible that excess weight and its cardiometabolic comorbidities may be the consequences of exposure to poor lifestyle choices that could also contribute to hearing loss. In other words, excess weight might be a proxy of unhealthy lifestyle habits. It is known that excess consumption of certain foods, particularly those that contain high amounts of refined grains, sugars, and trans fat, is associated with increased risks of obesity, DM, and CVD [68]. The Blue Mountains Hearing Study [69] showed that higher glycemic index was associated with an increased prevalence of hearing loss, whereas a higher dietary cereal fiber was inversely associated with the prevalence of hearing loss. Higher dietary glycemic load had a $76 \%$ higher odds of having hearing loss in all participants, while lower intake of carbohydrate and sugar was associated with a $62 \%$ and $72 \%$ lower odds of having hearing loss in the participants aged less than 70 years, respectively. Another interesting finding from the Blue Mountains Hearing Study [70] indicated that higher intake of dietary cholesterol was positively associated with prevalence of hearing loss, whereas treatment with statins and higher intake of dietary monounsaturated fats were inversely associated with prevalence of hearing loss. Of interest, a recent longitudinal cohort study of female nurses [71] suggests that adherence to the healthful dietary patterns that are often linked to a better cardiometabolic health was associated with a lower risk of hearing loss. Moreover, there is evidence that the incident [20] and prevalent $[20,72]$ of hearing loss is inversely associated with physical activity, a non-nutritional determinant for weight control that has been linked to a better cardiometabolic profile [73].

\section{Limitations}

The present meta-analysis should be interpreted within the context of its limitations. First, the present metaanalysis pooled the data from the observational studies.
Therefore, the unmeasured or residual confounders may also influence of the associations between BMI, WC, and the risk of hearing loss. For example, only few studies performed adjustment for important risk factors for hearing loss, such as longstanding noise exposure, medical conditions that may lead to hearing loss, and the use of ototoxic drugs. Moreover, we could not rule out the potential role of cardiometabolic comorbidities related to excess weight as mediators of the associations between BMI or WC and hearing loss. Second, we did not have enough data sets to investigate the associations between BMI or WC and hearing loss according to several important factors, such as type of hearing loss (sensorineural or age-related), frequency of hearing loss, and severity of hearing loss. The potential effect modification by these factors warrants further investigation. Third, slight variation in the cut-points (frequencies and threshold) used to define hearing loss among the included studies should also be considered. Finally, high heterogeneity observed across studies suggests that the findings should be treated with caution. Unfortunately, we were unable to pin-point the source of heterogeneity because subgroup analyses could not be performed. However, high heterogeneity appeared to be mainly caused by differences in the strength (significant vs. non-significant) of association across studies rather than differences in the direction (inverse vs positive) of association across studies as the vast majority of studies on elevated BMI (overweight and obesity) or higher WC showed a tendency toward positive associations, although some did not reach statistical significance.

\section{Conclusions}

In summary, our findings add weight to the evidence that elevated BMI and higher WC may be positively associated with the risk of hearing loss. However, the nature of the observed positive associations remains unclear because we were unable to consider the type and severity of hearing loss, noise exposure, and other potential effect modifiers or mediators in our analyses. These issues need to be addressed by well-performed prospective studies.

\section{Supplementary information}

Supplementary information accompanies this paper at https://doi.org/10. 1186/s12199-020-00862-9.

Additional file 1: Table S1. Characteristics of the included studies. Additional file 2: Table S2. The Newcastle Ottawa scale for cohort study.

Additional file 3: Table S3. The Newcastle Ottawa scale for crosssectional study.

\section{Abbreviations}

BMI: Body mass index; Cls: Confidence intervals; DM: Diabetes mellitus; HRs: Hazard ratios; NOS: Newcastle-Ottawa Scale; ORs: Odds ratios; RRs: Relative risks; WC: Waist circumference; WHO: World Health Organization 


\section{Acknowledgements}

Not applicable.

\section{Authors' contributions}

LQQ: conceptualization, funding acquisition, and supervision; JRY: formal analysis and writing-original draft preparation; KH: writing-reviewing and editing; CLC: methodology and software; YHL: methodology and software; JYX: funding acquisition and Supervision. The authors read and approved the final manuscript.

\section{Funding}

This research was funded by the National Natural Science Foundation of China (no. 81673101, 81973024). This study was also supported by the Priority Academic Program Development of Jiangsu Higher Education Institutions (PAPD).

\section{Availability of data and materials}

The datasets used and analyzed in the present study are available from the corresponding author upon reasonable request.

\section{Ethics approval and consent to participate}

Not applicable.

\section{Consent for publication}

Not applicable.

\section{Competing interests}

The authors declare that they have no competing interests.

\section{Author details}

${ }^{1}$ Department of Nutrition and Food Hygiene, School of Public Health, Soochow University, Suzhou 215123, China. ${ }^{2}$ Children's Hospital of Soochow University, Suzhou 215025, China. ${ }^{3}$ State Key Laboratory of Radiation Medicine and Protection, School of Radiation Medicine and Protection, Soochow University, Suzhou 215123, China.

\section{Received: 21 April 2020 Accepted: 18 June 2020}

\section{Published online: 26 June 2020}

\section{References}

1. Addressing the rising prevalence of hearing loss. http://apps.who.int/iris/ bitstream/handle/10665/260336/9789241550260-eng.pdf;jsessionid=C4D55 7BD8138C8CD22A49BF9CC3559D6? sequence=1 (2018).

2. Global, regional, and national incidence, prevalence, and years lived with disability for 328 diseases and injuries for 195 countries, 1990-2016: a systematic analysis for the Global Burden of Disease Study 2016. Lancet. 2017;390:1211-59. https://doi.org/10.1016/s0140-6736(17)32154-2.

3. Wilson BS, Tucci DL, Merson MH, O'Donoghue GM. Global hearing health care: new findings and perspectives. Lancet. 2017;390:2503-15. https://doi. org/10.1016/s0140-6736(17)31073-5.

4. Fellinger J, Holzinger D, Pollard R. Mental health of deaf people. Lancet. 2012;379:1037-44. https://doi.org/10.1016/s0140-6736(11)61143-4

5. Li CM, Zhang X, Hoffman HJ, Cotch MF, Themann CL, Wilson MR. Hearing impairment associated with depression in US adults, National Health and Nutrition Examination Survey 2005-2010. JAMA Otolaryngol Head Neck Surg. 2014;140:293-302. https://doi.org/10.1001/jamaoto.2014.42.

6. Mener DJ, Betz J, Genther DJ, Chen D, Lin FR. Hearing loss and depression in older adults. J Am Geriatr Soc. 2013;61:1627-9. https://doi.org/10.1111/jgs. 12429.

7. Stevenson J, Kreppner J, Pimperton H, Worsfold S, Kennedy C. Emotional and behavioural difficulties in children and adolescents with hearing impairment: a systematic review and meta-analysis. Eur Child Adolesc Psychiatry. 2015;24:477-96. https://doi.org/10.1007/s00787-015-0697-1.

8. Theunissen SC, Rieffe C, Netten AP, Briaire JJ, Soede W, Schoones JW, et al. Psychopathology and its risk and protective factors in hearing-impaired children and adolescents: a systematic review. JAMA Pediatr. 2014;168:1707. https://doi.org/10.1001/jamapediatrics.2013.3974.

9. Liljas AE, Wannamethee SG, Whincup PH, Papacosta O, Walters K, Iliffe S, et al. Hearing impairment and incident disability and all-cause mortality in older British community-dwelling men. Age Ageing. 2016:45:662-7. https:// doi.org/10.1093/ageing/afw080.
10. Basner M, Babisch W, Davis A, Brink M, Clark C, Janssen S, et al. Auditory and non-auditory effects of noise on health. Lancet. 2014;383:1325-32. https:// doi.org/10.1016/s0140-6736(13)61613-x.

11. Smith RJ, Bale JF Jr, White KR. Sensorineural hearing loss in children. Lancet. 2005;365:879-90. https://doi.org/10.1016/s0140-6736(05)71047-3.

12. Schreiber BE, Agrup C, Haskard DO, Luxon LM. Sudden sensorineural hearing loss. Lancet. 2010;375:1203-11. https://doi.org/10.1016/s01406736(09)62071-7.

13. Dhanda N, Taheri S. A narrative review of obesity and hearing loss. Int J Obes. 2017:41:1066-73. https://doi.org/10.1038/ijo.2017.32.

14. Horikawa C, Kodama S, Tanaka S, Fujihara K, Hirasawa R, Yachi Y, et al. Diabetes and risk of hearing impairment in adults: a meta-analysis. J Clin Endocrinol Metab. 2013;98:51-8. https://doi.org/10.1210/jc.2012-2119.

15. Gates GA, Cobb JL, D'Agostino RB, Wolf PA. The relation of hearing in the elderly to the presence of cardiovascular disease and cardiovascular risk factors. Arch Ptolaryngol Head Neck Surg. 1993;119:156-61.

16. Torre P 3rd, Cruickshanks KJ, Klein BE, Klein R, Nondahl DM. The association between cardiovascular disease and cochlear function in older adults. J Speech Lang Hearing Res. 2005;48:473-81. https://doi.org/10.1044/10924388(2005/032)

17. Wattamwar K, Qian ZJ, Otter J, Leskowitz MJ, Caruana FF, Siedlecki B, et al. Association of Cardiovascular Comorbidities With Hearing Loss in the Older Old. JAMA Otolaryngol Head Neck Surg. 2018;144:623-9. https://doi.org/10. 1001/jamaoto.2018.0643.

18. Helzner EP, Contrera KJ. Type 2 diabetes and hearing impairment. Curr Diabet Rep. 2016;16:3. https://doi.org/10.1007/s11892-015-0696-0.

19. Barrenas ML, Jonsson B, Tuvemo T, Hellstrom PA, Lundgren M. High risk of sensorineural hearing loss in men born small for gestational age with and without obesity or height catch-up growth: a prospective longitudinal register study on birth size in 245,000 Swedish conscripts. J Clin Endocrinol Metab. 2005;90:4452-6. https://doi.org/10.1210/jc.2005-0385.

20. Curhan SG, Eavey R, Wang M, Stampfer MJ, Curhan GC. Body mass index, waist circumference, physical activity, and risk of hearing loss in women. Am J Med. 2013;126:1142.e1-8. https://doi.org/10.1016/j.amjmed.2013.04.026.

21. Cruickshanks KJ, Nondahl DM, Dalton DS, Fischer ME, Klein BE, Klein R, et al. Smoking, central adiposity, and poor glycemic control increase risk of hearing impairment. J Am Geriatr Soc. 2015;63:918-24. https://doi.org/10.1111/jgs.13401.

22. Lohi V, Hannula S, Ohtonen P, Sorri M, Maki-Torkko E. Hearing impairment among adults: the impact of cardiovascular diseases and cardiovascular risk factors. Int J Audiol. 2015;54:265-73. https://doi.org/10.3109/14992027.2014.974112.

23. Kim SH, Won YS, Kim MG, Baek YJ, Oh IH, Yeo SG. Relationship between obesity and hearing loss. Acta Otolaryngol. 2016;136:1046-50. https://doi. org/10.1080/00016489.2016.1179787.

24. Aghazadeh-Attari J, Mansorian B, Mirza-Aghazadeh-Attari M, Ahmadzadeh J, Mohebbi I. Association between metabolic syndrome and sensorineural hearing loss: a cross-sectional study of 11,114 participants. Diabet Metabol Syndrome Obes. 2017;10:459-65. https://doi.org/10.2147/dmso.s150893.

25. Tan HE, Lan NSR, Knuiman MW, Divitini ML, Swanepoel DW, Hunter M, et al. Associations between cardiovascular disease and its risk factors with hearing loss-A cross-sectional analysis. Clin Otolaryngol. 2018;43:172-81. https://doi. org/10.1111/coa.12936.

26. Han X, Wang Z, Wang J, Li Y, Hu H, Hu Y, et al. Metabolic syndrome is associated with hearing loss among a middle-aged and older Chinese population: a cross-sectional study. Ann Med. 2018;50:587-95. https://doi. org/10.1080/07853890.2018.1469786.

27. Wang J, Sung V, Lycett K, Carew P, Liu RS, Grobler A, et al. How body composition influences hearing status by mid-childhood and mid-life: The Longitudinal Study of Australian Children. Int J Obes. 2018;42:1771-81. https://doi.org/10.1038/s41366-018-0170-6.

28. Hu H, Tomita K, Kuwahara K, Yamamoto M, Uehara A, Kochi T, et al. Obesity and risk of hearing loss: a prospective cohort study. Clin Nutr. 2019. https:// doi.org/10.1016/j.clnu.2019.03.020.

29. Shargorodsky J, Curhan SG, Eavey R, Curhan GC. A prospective study of cardiovascular risk factors and incident hearing loss in men. Laryngoscope. 2010;120:1887-91. https://doi.org/10.1002/lary.21039.

30. Sogebi OA. Assessment of the risk factors for hearing loss in adult Nigerian population. Nigerian Med J. 2013;54:244-9. https://doi.org/10.4103/03001652.119648.

31. Sumit AF, Das A, Sharmin Z, Ahsan N, Ohgami N, Kato M, et al. Cigarette smoking causes hearing impairment among Bangladeshi population. PLoS One. 2015;10:e0118960. https://doi.org/10.1371/journal.pone.0118960. 
32. Jung da J, Jang JH, Lee KY. Is body mass index associated with the development of age-related hearing impairment in Koreans? The Korean National Health and Nutrition Examination Survey 2009-2012. Clin Exp Otorhinolaryngol. 2016;9:123-30. https://doi.org/10.21053/ceo.2015.00955.

33. Stroup DF, Berlin JA, Morton SC, Olkin I, Williamson GD, Rennie D, et al. Meta-analysis of observational studies in epidemiology: a proposal for reporting. Meta-analysis Of Observational Studies in Epidemiology (MOOSE) group. Jama. 2000;283:2008-12

34. Wells GA SB, O'connell D, et al.: The Newcastle-Ottawa Scale (NOS) for assessing the quality of nonrandomized studies in meta-analyses. http:// www.ohri.ca/programs/clinical_epidemiology/oxford.asp (2000).

35. Zhang J, Yu KF. What's the relative risk? A method of correcting the odds ratio in cohort studies of common outcomes. Jama. 1998:280:1690-1. https://doi.org/10.1001/jama.280.19.1690.

36. DerSimonian R, Laird N. Meta-analysis in clinical trials. Control Clin Trials. 1986;7:177-88

37. (WHO) WHO: Body mass index-BMI. http://www.euro.who.int/en/healthtopics/disease-prevention/nutrition/a-healthy-lifestyle/body-mass-index-bmi.

38. Greenland S, Longnecker MP. Methods for trend estimation from summarized dose-response data, with applications to meta-analysis. Am J Epidemiol. 1992:135:1301-9.

39. Orsini N, Bellocco R, Greenland S. Generalized least squares for trend estimation of summarized dose-response data. Stata J. 2006:6:40-57.

40. Higgins JP, Thompson SG, Deeks JJ, Altman DG. Measuring inconsistency in meta-analyses. BMJ (Clin Res Ed). 2003;327:557-60. https://doi.org/10.1136/ bmj.327.7414.557.

41. Egger M, Davey Smith G, Schneider M, Minder C. Bias in meta-analysis detected by a simple, graphical test. BMJ (Clin Res Ed). 1997;315:629-34. https://doi.org/10.1136/bmj.315.7109.629.

42. Duval S, Tweedie R. Trim and fill: A simple funnel-plot-based method of testing and adjusting for publication bias in meta-analysis. Biometrics. 2000; 56:455-63.

43. Kohlberg GD, Demmer RT, Lalwani AK. Adolescent obesity is an independent risk factor for sensorineural hearing loss: results from the national health and nutrition examination survey 2005 to 2010. Otology Neurotol. 2018;39:1102-8. https://doi.org/10.1097/mao.0000000000001956.

44. Lalwani AK, Katz K, Liu YH, Kim S, Weitzman M. Obesity is associated with sensorineural hearing loss in adolescents. Laryngoscope. 2013;123:3178-84. https://doi.org/10.1002/lary.24244.

45. Lee JS, Kim DH, Lee HJ, Kim HJ, Koo JW, Choi HG, et al. Lipid profiles and obesity as potential risk factors of sudden sensorineural hearing loss. PLoS One. 2015;10:e0122496. https://doi.org/10.1371/journal.pone.0122496.

46. Hong JW, Jeon JH, Ku CR, Noh JH, Yoo HJ, Kim D-J. The prevalence and factors associated with hearing impairment in the Korean adults: the 20102012 Korea National Health and Nutrition Examination Survey (observational study). Medicine. 2015:94

47. Michikawa T, Nakamura T, Imamura H, Mizutari K, Saito H, Takebayashi T, et al. Markers of Overall Nutritional Status and Incident Hearing Impairment in Community-Dwelling Older Japanese: The Kurabuchi Study. J Am Geriatr Soc. 2016;64:1480-5. https://doi.org/10.1111/jgs.14245.

48. McKee MM, Stransky ML, Reichard A. Hearing loss and associated medical conditions among individuals 65 years and older. Disabil Health J. 2018;11: 122-5. https://doi.org/10.1016/j.dhjo.2017.05.007.

49. Engdahl B, Aarhus L, Lie A, Tambs K. Cardiovascular risk factors and hearing loss: The HUNT study. Int J Audiol. 2015;54:958-66. https://doi.org/10.3109/ 14992027.2015.1090631.

50. 2012 WHO: Prevention of blindness and deafness: grades of hearing impairment. https://www.who.int/news-room/fact-sheets/detail/deafnessand-hearing-loss. Accessed Last accessed January 1, 2019.

51. Kershaw EE, Flier JS. Adipose tissue as an endocrine organ. J Clin Endocrinol Metab. 2004;89:2548-56. https://doi.org/10.1210/jc.2004-0395.

52. Ouchi N, Parker JL, Lugus JJ, Walsh K. Adipokines in inflammation and metabolic disease. Nat Rev Immunol. 2011;11:85-97. https://doi.org/10.1038/ nri2921.

53. McMaster WG, Kirabo A, Madhur MS, Harrison DG. Inflammation, immunity, and hypertensive end-organ damage. Circ Res. 2015;116:1022-33. https:// doi.org/10.1161/circresaha.116.303697.

54. Trune DR, Nguyen-Huynh A. Vascular Pathophysiology in Hearing Disorders. Semin Hear. 2012;33:242-50. https://doi.org/10.1055/s-0032-1315723.

55. Chandran M, Phillips SA, Ciaraldi T, Henry RR. Adiponectin: more than just another fat cell hormone? Diabetes Care. 2003;26:2442-50.
56. Weyer C, Funahashi T, Tanaka S, Hotta K, Matsuzawa Y, Pratley RE, et al. Hypoadiponectinemia in obesity and type 2 diabetes: close association with insulin resistance and hyperinsulinemia. J Clin Endocrinol Metab. 2001;86: 1930-5. https://doi.org/10.1210/jcem.86.5.7463.

57. Hwang JH, Hsu CJ, Liu TC, Yang WS. Association of plasma adiponectin levels with hearing thresholds in adults. Clin Endocrinol. 2011;75:614-20. https://doi.org/10.1111/j.1365-2265.2011.04090.x.

58. Wu CC, Tsai CH, Lu YC, Lin HC, Hwang JH, Lin YH, et al. Contribution of adiponectin and its type 1 receptor to age-related hearing impairment. Neurobiol Aging. 2015;36:2085-93. https://doi.org/10.1016/j.neurobiolaging. 2015.02.030

59. Tanigawa T, Shibata R, Ouchi N, Kondo K, Ishii M, Katahira N, et al. Adiponectin deficiency exacerbates age-related hearing impairment. Cell Death Dis. 2014;5:e1189. https://doi.org/10.1038/cddis.2014.140.

60. Yamasoba T, Lin FR, Someya S, Kashio A, Sakamoto T, Kondo K. Current concepts in age-related hearing loss: epidemiology and mechanistic pathways. Hear Res. 2013;303:30-8. https://doi.org/10.1016/j.heares.2013.01. 021.

61. Lee MJ, Wu Y, Fried SK. Adipose tissue heterogeneity: implication of depot differences in adipose tissue for obesity complications. Mol Asp Med. 2013; 34:1-11. https://doi.org/10.1016/j.mam.2012.10.001.

62. Janssen I, Katzmarzyk PT, Ross R. Waist circumference and not body mass index explains obesity-related health risk. Am J Clin Nutr. 2004;79:379-84.

63. Casanueva FF, Moreno B, Rodriguez-Azeredo R, Massien C, Conthe P, Formiguera $X$, et al. Relationship of abdominal obesity with cardiovascular disease, diabetes and hyperlipidaemia in Spain. Clin Endocrinol. 2010;73:3540. https://doi.org/10.1111/j.1365-2265.2009.03727.x.

64. Huxley R, Mendis S, Zheleznyakov E, Reddy S, Chan J. Body mass index, waist circumference and waist:hip ratio as predictors of cardiovascular risk-a review of the literature. Eur J Clin Nutr. 2010;64:16-22. https://doi.org/10. 1038/ejcn.2009.68.

65. Helzner EP, Patel AS, Pratt S, Sutton-Tyrrell K, Cauley JA, Talbott E, et al. Hearing sensitivity in older adults: associations with cardiovascular risk factors in the health, aging and body composition study. J Am Geriatr Soc. 2011;59:972-9. https://doi.org/10.1111/j.1532-5415.2011.03444.x.

66. Fransen E, Topsakal V, Hendrickx J-J, Van Laer L, Huyghe JR, Van Eyken E, et al. Occupational noise, smoking, and a high body mass index are risk factors for age-related hearing impairment and moderate alcohol consumption is protective: a European population-based multicenter study. J Assoc Res Otolaryngol. 2008;9:264-76.

67. Hwang JH, Wu CC, Hsu CJ, Liu TC, Yang WS. Association of central obesity with the severity and audiometric configurations of age-related hearing impairment. Obesity (Silver Spring, Md). 2009;17:1796-801. https://doi.org/ 10.1038/oby.2009.66.

68. Mozaffarian D. Dietary and policy priorities for cardiovascular disease, diabetes, and obesity: a comprehensive review. Circulation. 2016;133:187225. https://doi.org/10.1161/circulationaha.115.018585.

69. Gopinath B, Flood VM, McMahon CM, Burlutsky G, Brand-Miller J, Mitchell P. Dietary glycemic load is a predictor of age-related hearing loss in older adults. J Nutr. 2010;140:2207-12. https://doi.org/10.3945/jn.110.128462.

70. Gopinath B, Flood VM, Teber E, McMahon CM, Mitchell P. Dietary intake of cholesterol is positively associated and use of cholesterol-lowering medication is negatively associated with prevalent age-related hearing loss. J Nutr. 2011;141:1355-61. https://doi.org/10.3945/jn.111.138610.

71. Curhan SG, Wang M, Eavey RD, Stampfer MJ, Curhan GC. Adherence to healthful dietary patterns is associated with lower risk of hearing loss in women. J Nutr. 2018;148:944-51. https://doi.org/10.1093/jn/nxy058.

72. Haas PJ, Bishop CE, Gao Y, Griswold ME, Schweinfurth JM. Relationships among measures of physical activity and hearing in African Americans: The Jackson Heart Study. Laryngoscope. 2016;126:2376-81. https://doi.org/10. 1002/lary.25924.

73. Hidayat K, Zhou HJ, Shi BM. Influence of physical activity at a young age and lifetime physical activity on the risks of 3 obesity-related cancers: systematic review and meta-analysis of observational studies. Nutr Rev. 2020;78:1-18. https://doi.org/10.1093/nutrit/nuz024.

\section{Publisher's Note}

Springer Nature remains neutral with regard to jurisdictional claims in published maps and institutional affiliations. 